Dossiê: Conferência de Medellín: 50 anos - Artigo Original (c) (1)

\title{
Medellín como acontecimiento sinodal. Una eclesialidad colegiada fecundada y completada
}

\author{
Medellín as synodal event. A collegial ecclesiality begotten and accomplished
}

Rafael Luciani*

\begin{abstract}
Resumen
Medellín supuso una recepción única del Concilio Vaticano II que llevó a la Iglesia latinoamericana a posicionarse como una Iglesia fuente, una Iglesia que no solo había creado una forma colegial de interactuar a nivel continental con la creación del Celam, sino que inauguró un espíritu de ser y trabajar y un modo de interacción que dieron paso a una forma de proceder que caracterizaría a su identidad. En este sentido, nos proponemos leer a Medellín como acontecimiento que no puede ser reducido a un texto. La forma en la que se procedió, más ambiental que tematizada, dio pié a un espíritu de convergencia profética que tomó cuerpo en el método de trabajo, el modo de relación entre los participantes, la liturgia diaria, la disposición para la escucha y la discusión abierta entre todos. En este artículo explicamos como todo esto inauguró una eclesialidad única, cuya práctica colegial fue fecundada y completada por un espíritu sinodal que logró profundizar y concretar al modelo de Iglesia Pueblo de Dios del Concilio Vaticano II.
\end{abstract}

Palabras-clave: Medellín; colegialidad; sinodalidad; Pueblo de Dios; Iglesia Latinoamericana.

\begin{abstract}
The Medellin Conference represented a unique reception of the Second Vatican Council, positioning the Latin American Church as a Source Church. This Conference not only created a collegial way of interacting at a continental level through the Latin American Council of Bishops (CELAM), but also inaugurated a way of being and working, and a mode of interaction that gave birth to a way of proceeding that would characterize the Latin American Church own's identity. In this article, we understand Medellín as an epochal event that can not be reduced to a mere text. The way in which the Conference proceeded, more environmental than thematized, gave rise to a spirit of prophetic convergence among bishops, priests, religious and lay, that took shape in the method of work, the relationships among the participants, the daily liturgy, the disposition for listening and having open discussions among all. In this article we explain how all this inaugurated a unique ecclesiality inspired by a collegial practice, and completed by a Synodal Spirit that advanced the ecclesial model of People of God of the Second Vatican Council.
\end{abstract}

Keywords: Medellín; Collegiality; Sinodality; People of God; Latin American Church.

Artigo submetido em 30 de maio de 2018 e aprovado em 10 de julho de 2018.

* Doctor en Teología por la Pontificia Università Gregoriana de Roma. Profesor de la Universidad Católica Andrés Bello (Caracas) y de la Escuela de Teología y Ministerio (Boston College). País de origem: Venezuela. E-mail: rafluciani@gmail.com

Horizonte, Belo Horizonte, v. 16, n. 50, p. 482-516, maio/ago. 2018 - ISSN 2175-5841 


\section{Introducción}

El 23 de noviembre de 1965, días antes de la clausura del Concilio Vaticano II, el Papa Pablo VI convocó a los obispos latinoamericanos, por la celebración del décimo aniversario del Consejo Episcopal Latinoamericano (Celam), para animarlos a elaborar un Plan Pastoral Continental (PABLO VI, 1965), un proyecto que expresara la recepción conciliar inmediata y la articulación de una identidad propia para la Iglesia en América Latina (MCGRATH, 1989, p. 152-179). Con este impulso, el 20 de enero de 1968 Pablo VI anunció la convocatoria a la Segunda Conferencia General del Episcopado Latinoamericano y, el 24 de agosto de 1968, la inauguró con un discurso que pronunció en la Catedral de Bogotá. Las sesiones de trabajo se realizaron en el Seminario de Medellín entre el 26 de agosto y el 6 de septiembre de ese año.

La Conferencia reunida bajo el lema La Iglesia en la actual transformación de América Latina a la luz del Concilio entregó dieciséis documentos que supusieron una conciencia de que "los hechos sociales requieren de ella (de la Iglesia) una presencia eficaz que no se agota con la promoción de la santidad personal por la predicación y los sacramentos” (MEJÍA, 1968, p. 688). sino que comporta el seguimiento de "Jesucristo que vive en los hermanos necesitados o muere en ellos” (MEJÍA, 1968, p. 689). Esta conciencia quedó plasmada en la manera en la que se dispusieron los textos, lo que representó una innovación respecto del Concilio, como lo reconoce Marcos McGrath: "La división en tres áreas: Promoción humana, Evangelización y crecimiento en la fe, e Iglesia visible y sus estructuras, altera el orden más frecuentemente usado en la Iglesia, antes y después de Medellín. Evangelización y crecimiento en la fe viene después de la Promoción humana” (MCGRATH, 1989, p. 165-166).

El contexto exigía releer la idea de una única historia en la que Dios se autocomunica desde una lógica de correspondencias - realizar en la Iglesia los cambios que se piden a la sociedad-y consecuencias - conversión de corazones y de estructuras. De este modo, la vida cristiana y los canales de su transmisión - 
personas e instituciones-manifestarían siempre "la unidad profunda que existe entre el proyecto salvífico de Dios, realizado en Cristo, y las aspiraciones del hombre; entre la historia de la salvación y la historia humana; entre la Iglesia, Pueblo de Dios, y las comunidades temporales; entre la acción reveladora de Dios y la experiencia del hombre; entre los dones y carismas sobrenaturales y los valores humanos" (Catequesis 4).

Es así que lo pastoral, como modo de obrar de la Iglesia en el mundo, se convertía en el lugar hermenéutico por el que la doctrina era recibida, reflexionada y transmitida, lo cual reclamaba de la institución una dinámica permanente de conversión. Esta visión entrañaba combinar, recíprocamente, dos principios conciliares: el de la reformabilidad de la Iglesia y el de la pastoralidad de la doctrina, sin los cuales no se puede asimilar el salto cualitativo más radical que dio Medellín hasta el día de hoy: haber entendido que el modelo de Iglesia Pueblo de Dios solo se realiza en la construcción de una eclesialidad colegiada en forma sinodal, como iremos desarrollando en el siguiente artículo.

\section{De Iglesia reflejo a Iglesia fuente}

Medellín supuso el paso de una Iglesia reflejo a una Iglesia adulta, hoy convertida en Iglesia fuente (LIMA VAZ, 1968, p. 17-22), que supo discernir el talante de la época al asumir que el sujeto humano "queda definido principalmente por la responsabilidad hacia sus hermanos y ante la historia" (GS 55). En las palabras de clausura de monseñor Juan Landazuri Ricketts se aprecia esta opción con gran claridad profética:

Hay algo muy característico en los planteamientos que nos hemos hecho durante estos días y que deseo subrayar. Es esto: nosotros enfrentamos nuestros problemas. Hay una servidumbre que no es comunión. Hay una dependencia, psicológica y sociológica, que no responde a la íntima trabazón del Cuerpo del Señor. Encarar nuestros problemas exige madurez. Al hacerlo encontramos la dimensión propia de nuestro episcopado ya que cada uno de nosotros somos guías de una determinada y concreta Iglesia local $\mathrm{y}$, todos juntos, de este irreversible momento histórico nuestro latinoamericano. (LANDAZURI RICKETTS, 1969, p. 250). 
Este modo de posicionarse en el mundo representó un salto cualitativo que superaba el modelo eclesial de la I Conferencia General del Episcopado Latinoamericano celebrada en Río, en 1955, cuya visión, intraeclesial y autorreferencial, admitió como el gran problema de la época la insuficiencia de cleroํ․ También comportó un salto cualitativo metodológico respecto del Concilio, pues no solo asumió el método ver, juzgar y actuar proveniente de la Juventud Obrera Católica (JOC) de Joseph Cardijn inspirado en la teología de los signos de los tiempos de Gaudium et Spes, sino que se preocupó, concretamente, por “proponer líneas de acción pastoral, con el fin de transformar, en la dirección del Reino de Dios y la liberación de los pobres, las realidades traspasadas por estructuras de pecado, y por el clamor y la esperanza de los pequeños" (BEOZZO, 1998, p. 828). Esto hace que Medellín instale un discurso con sujeto social y adultez cristiana que lleva a los obispos a comprometerse a producir los cambios que demandaban a la sociedad. Por ello se acepta que "no basta reflexionar, lograr mayor clarividencia y hablar; es menester obrar (...). Esta asamblea fue invitada a 'tomar decisiones y a establecer proyectos, solamente si estábamos dispuestos a ejecutarlos como compromiso personal nuestro, aun a costa de sacrificio"” (Introducción 3).

La razón de esta opción no es sociológica, y menos aún ideológica. Es cristológica. Se trataba de "saber escuchar al mundo porque en él, en los hombres y en los acontecimientos, pese a las fallas humanas, está el Señor Jesús, fuente y remate de todo existir y de todo acaecer" (LANDAZURI RICKETTS, 1968). En estas palabras del cardenal Landazuri Ricketts resuena el espíritu conciliar que llama a prestar oídos a "los gozos y las esperanzas, las tristezas y las angustias de los hombres de nuestro tiempo, sobre todo de los pobres y de cuantos sufren", pues “son a la vez gozos y esperanzas, tristezas y angustias de los discípulos de Cristo” (Gaudium et Spes 1). Los obispos reunidos en Medellín responderán: "Oímos el grito que sube de vuestro sufrimiento" (Pobreza 2). De este modo se propició una

\footnotetext{
${ }^{1}$ En su carta apostólica Ad Ecclesiam Christi, Pío XII propone el tema como el marco de discernimiento de la Conferencia al indicar que es "el más grave y peligroso, y que aún no ha recibido cumplida solución: la insuficiencia de clero".
}

Horizonte, Belo Horizonte, v. 16, n. 50, p. 482-516, maio/ago. 2018 - ISSN 2175-5841 
forma de proceder desde abajo y desde adentro porque "para conocer a Dios es necesario conocer el hombre" (Introducción 1), ese hombre situado en "la trama de acontecimientos y hechos significativos que es la historia" (Movimientos de laicos 9).

A diferencia del Concilio, Medellín no se sitúa ante la historia de manera genérica, sino en la historicidad, en la trama y quehacer que configuran la cotidianidad y los sistemas sociales, y lo hace a la luz de la dimensión de acción pastoral de la Iglesia. Su compromiso evangelizador no se puede separar de los esfuerzos por lograr una "mayor personalización y cohesión fraterna" en la sociedad (Introducción 4). Con responsabilidad aceptó el espíritu conciliar que había declarado que no era posible escuchar la voz de Dios sin oír "las múltiples voces de nuestro tiempo" (GS 44) y encontrar en ellas "la presencia de Dios que quiere salvar al hombre entero" (Introducción 5).

\section{Ampliar y completar la colegialidad}

\subsection{Una experiencia ambiental, no tematizada}

América Latina ya contaba con una estructura colegiada cuando se inicia el Concilio. La creación del Consejo Episcopal Latinoamericano en 1955 había inaugurado un estilo de trabajo además de un flujo comunicacional permanente, de tipo orgánico e institucional, entre las distintas Iglesias locales latinoamericanas y caribeñas representadas a través de sus conferencias episcopales. Su carácter organizacional y consultivo, definido en sus primeros estatutos como "órgano de contacto y colaboración", fue facilitando la configuración de un método auténticamente de la región. En su Crónica de Medellín, Hernán Parada relata:

los nuevos conceptos y los nuevos métodos de trabajo que, por su misma originalidad, hacían, inconscientemente, pensar en sus influencias europeas (de donde siempre se ha supuesto que debe venir todo lo bueno) son, en realidad, creaciones genuinamente latinoamericanas. La Iglesia Católica del continente cumple en esta hora de autenticidad americanista, y a través de este organismo, con dar su aporte propio. (PARADA, 1975, p. 36).

Horizonte, Belo Horizonte, v. 16, n. 50, p. 482-516, maio/ago. 2018 - ISSN 2175-5841 
Esta manera de trabajar que emergía en la Iglesia fue dando forma a una identidad regional del clero con una mayor conciencia de su contribución teológica y eclesial. Si bien es cierto que la tematización de la colegialidad ocurrió durante el Concilio, su práctica ya existía entre los obispos latinoamericanos “afirmando efectivamente su vínculo unitivo y su conciencia común" (FERRÉ, 2018). Cecilio de Lora lo apunta en los siguientes términos:

diez años antes de que el Concilio Vaticano II promulgue la doctrina de la colegialidad episcopal (LG 22), la Iglesia latinoamericana la ponía en marcha, no con palabras sino con obras y de verdad: algo realmente profético que serviría más tarde de modelo para otras Iglesias por toda la geografía de la Iglesia universal. (DE LORA, 2011, p. 1234).

La dinámica colegial que inaugura el Celam se aprecia en su carácter de organismo de contacto y colaboración permanente que tiene su base en los principios de corresponsabilidad entre distintas conferencias episcopales locales (Pastoral de conjunto 29-33). Durante el Concilio, cuando otras Iglesias locales apreciaban a la latinoamericana como un cuerpo diferenciado, pero no separado, del conjunto del colegio de obispos, este modelo destacó por su originalidad. El obispo McGrath refiere cómo el Celam mantuvo este espíritu unitario en el Concilio:

durante los cuatro años del Concilio, en el período de las sesiones y por reuniones y conferencias entre sesiones, el Celam mantenía los contactos e informaba a todos sus obispos miembros. En las sesiones vespertinas y por la noche varias veces por semana se nos fue preparando en los temas conciliares, por nuestro propio personal (peritos, teólogos, etc.) o invitados. Mantuvo también el obispo Larraín desde el segundo año del Concilio, cuando fue elegido presidente del Celam, muchos contactos con otras conferencias episcopales, y con el famoso grupo de los 'Jueves', que analizaba y enfocaba en reuniones informales, cada semana, la marcha del Concilio. (MCGRATH, 2000, p. 32).

De toda esta experiencia, concluirá McGrath, que "el Concilio fue desarrollado no solamente para enseñar y orientar a toda la Iglesia, también representó una escuela de formación para nosotros los obispos. Fue una lección práctica de lo que era la comunión eclesial y la colegialidad episcopal” (MCGRATH, 
2000, p. 32). En fin, allí se facilitó una experiencia de comunión entre los obispos latinoamericanos que los fortaleció en su identidad regional y en el intercambio fraterno, porque se reconoció

La experiencia diaria del contacto de los participantes entre sí (...). Durante el Concilio, Roma fue también el lugar donde nosotros, los latinoamericanos, teniendo la ocasión de vernos día tras día durante las sesiones, y esto durante cuatro años, llegamos a conocernos bien unos a otros y a sentir comunes nuestras situaciones y nuestras decisiones, en contraste, pero en comunión con la más extensa Iglesia universal. (MCGRATH, 1989, p. 160-161).

\subsection{La ampliación de la colegialidad}

Podemos decir que sus participantes llegan a Medellín con una práctica ambiental $^{2}$ de la doctrina de la colegialidad, aún no tematizada, pero vivida en el modo de leer la Palabra, orar, interrelacionarse, reflexionar y actuar en conjunto como cuerpo episcopal. De este hábito fue emergiendo un modo sinodal de proceder que tiene su raíz en la conciencia sociocultural regional de estar caminando (odos) juntos (syn). Jorge Mejía lo describe con gran intuición:

el episcopado latinoamericano y demás miembros de la asamblea fueron haciendo poco a poco la experiencia del valor que tiene en la vida de la Iglesia el intercambio fraterno de pastores entre sí y con el pueblo del Señor, para el descubrimiento de las soluciones aptas o bien simplemente para la recta visión de los problemas. (MEJÍA, 1968, p. 687).

La unidad entre pastoralidad y doctrina que acontecía en América Latina mucho antes del Concilio, permitió vivir la colegialidad de un modo diferente a su forma tradicional y jurídica, con un espíritu y una dinámica propios. El hecho de que los obispos realmente representaban a una portio Populi Dei y vivían su ministerio situados en este mundo y al servicio pastoral de la gente hizo que la conciencia de pertenencia al coetus no se entendiera sin una referencia esencial, real, al pueblo y sus circunstancias históricas. Como se advierte en Medellín, una

\footnotetext{
${ }^{2}$ Cuando hablamos de una práctica ambiental ya existente, entendemos que "el habla se da en un clima existencial. Es lo que se llama el co-encontrarse, el co-comprender y la articulación de sentido que se da siempre ya antes del decir mismo" (KUSCH, 1976, p. 108). Es un habitar el mundo que se traduce en costumbre no necesariamente explícita o tematizada a nivel de la conciencia, pero real, vivida como "forma peculiar de ser. Este ser está condicionado por todo aquello de cómo se viene estando" (KUSCH, 1976, p. 111).
}

Horizonte, Belo Horizonte, v. 16, n. 50, p. 482-516, maio/ago. 2018 - ISSN 2175-5841 
parte del pueblo estaba llamada a constituir "una Iglesia particular, en que se encuentra y opera verdaderamente la Iglesia de Cristo que es una, santa, católica y apostólica" (Pastoral de conjunto 17). Había una colegialidad situada que luego se fue perdiendo cuando se interpretó que la colegialidad venía dada por la ordenación episcopal per se y era posible la existencia de obispos sin representatividad de una portio Populi Dei, es decir, funcionarios sin ejercicio ministerial y, por tanto, doctrina sin pastoralidad. Landazuri Ricketts en su discurso de clausura describió en su esencia la personalidad colegial vivida en el encuentro a la luz de su dimensión pastoral:

creemos que es muy provechoso comprobar, en razón de todas las implicancias pastorales que lleva consigo, que la personalidad colegial de nuestro quehacer proviene precisamente de una vivencia, gozosamente acentuada durante estos días, de nuestra comunión episcopal situada en este mundo y en esta hora. En efecto, la realidad sacramental de nuestra colegialidad radica exactamente en nuestra comunión con una historia cuya profundidad específica reside en una 'convergencia de circunstancias proféticas. (LANDAZURI RICKETTS, 1969, p. 248).

Un modo pastoral de estar situados en la historia, en comunión con los pueblos que la habitan, determina y amplía el ejercicio de la colegialidad, y establece un balance entre la communio fidelium, la communio hierarchica y la communio ecclesiarum, todas ellas vividas desde la igualdad que concede la dignidad bautismal y el sacerdocio común. Medellín entiende que la comunión episcopal no existe en razón de la autopreservación de la communio hierarchica. Por ello, Landazuri Ricketts insiste en que "la profundización en nuestra colegialidad nos permite entrever el sentido de nuestra acción pastoral en las dimensiones latinoamericanas; ella determina nuestra acción” (LANDAZURI RICKETTS, 1969, p. 250-251). Y advierte: "Pero hay algo más: la presencia de los pobres debe cualificar y finalizar nuestros planes de pastoral de conjunto" (LANDAZURI RICKETTS, 1969, p. 252). Va teniendo lugar, pues, una ampliación progresiva de la colegialidad en razón de la vivencia del principio de pastoralidad cualificado por una clara opción por los pobres, fundado sobre la eclesiología del Pueblo de Dios. 
Mejía resume las formulaciones cuando asienta que "hubo ante todo, una experiencia de la colegialidad episcopal, fecundada y completada por la experiencia de la comunión de todos y cada uno que es la Iglesia” (MEJÍA, 1968, p. 687). Es interesante notar que insiste en que la comunión de todos y cada uno da un carácter de completitud a la colegialidad episcopal. Se puede hablar así de una práctica ambiental de la corresponsabilidad de todos -laicos, presbíteros, obispos- en pro del bien común del Pueblo de Dios y como consecuencia de la pastoralidad del acto colegial. Sin embargo, hay que recordar que la palabra corresponsabilidad y su ampliación al laicado en relación con el funcionamiento y el manejo de las relaciones de poder en la Iglesia, no están presentes en el Concilio. Lo más cercano puede hallarse en la Lumen Gentium:

los sagrados Pastores reconozcan y promuevan la dignidad y responsabilidad de los laicos en la Iglesia. Recurran gustosamente a su prudente consejo, encomiéndenles con confianza cargos en servicio de la Iglesia y denles libertad y oportunidad para actuar; más aún, anímenles incluso a emprender obras por propia iniciativa. (LG 37).

De acuerdo con la Lumen Gentium, la responsabilidad del laico no se justifica como participación en la responsabilidad del ministerio episcopal (lo que haría del laico un servidor del obispo), sino a partir de una auténtica colaboración recíproca que deviene corresponsabilidad en la expresión de un caminar juntos como bautizados por la misma Iglesia. Y es que la corresponsabilidad, por lo que se deduce del Vaticano II y del modo de operar del Celam, se fundamenta en la común identidad bautismal de los miembros de la Iglesia, donde todos son responsables de la comunión y de la misión eclesial. Esta identidad ha de ser vivida en la comunidad eclesial - no individual o privadamente- y de modo horizontal por todos los sujetos que hacen vida en el Pueblo de Dios. Por ello, se lee en Medellín que "en la comunidad los laicos, por su sacerdocio común, gozan del derecho y tienen el deber de aportar una indispensable colaboración a la acción pastoral. Por esto, es deber de los sacerdotes dialogar con ellos no de una manera ocasional, sino de modo constante e institucional" (Sacerdotes 16).

Horizonte, Belo Horizonte, v. 16, n. 50, p. 482-516, maio/ago. 2018 - ISSN 2175-5841 
Una manera tal de asumir y ejercer la corresponsabilidad que ocurrió en América Latina hizo visible la unidad y la comunión entre todas las Iglesias locales del continente, y las afilió a la Iglesia universal con una identidad regional o continental propia. Fue una auténtica communio ecclesiarum. Es posible captar aquí indicios de lo que José Oscar Beozzo entrevió como el ejercicio de una colegialidad ampliada en Medellín, cuya novedad, a su juicio, se encuentra básicamente en el método de trabajo adoptado por la asamblea, que no se repitió en ninguna otra conferencia episcopal de la región latinoamericana ni en la Iglesia más amplia de ese mismo modo. Allí se consiguió superar una visión de la colegialidad reducida a una mera función consultiva del Romano Pontífice 3 , y puso en práctica "una noción ampliada de la colegialidad, que implica al conjunto del Pueblo de Dios en las responsabilidades de la vida y la misión de la Iglesia” (BEOZZO, 1998, p. 833).4

Un caso concreto puede encontrarse en la redacción del documento conclusivo Movimientos de seglares que no fue aprobado en la primera votación de la sesión plenaria correspondiente porque los mismos obispos reclamaron que la comisión no estuvo integrada inicialmente por seglares, ya que ellos habían sido distribuidos en otras comisiones según sus especialidades. Luego los obispos decidieron que los seglares se reunieran entre sí y redactaran sus propias conclusiones, las cuales fueron aprobadas por unanimidad en una nueva sesión plenaria (MÚNERA, 1968, p. 400-401). Por ello es que se reconoce que, más allá del método explícitamente asumido, se vivió un clima de discernimiento sinodal que fue configurándose con base en un espíritu de colaboración, comunión, respeto de las competencias e integración de la persona adecuada al puesto justo. 5

\footnotetext{
3 "Medellín constitui, assim, um modelo alternativo a maneira de se exercer a colegialidade episcopal consubstanciada nos Sínodos dos Bispos, reduzidos a condição de um órgão consultivo do Romano Pontífice." (BEOZZO, 1998, p. 832).

4 "Esta noção alargada de colegialidade, implicando o conjunto do povo de Deus nas responsabilidades pela vida e missão da Igreja, esteve esboçadas na mecânica de trabalho adotada em Medellín e, em parte, nas votações ali realizadas." (BEOZZO, 1998, p. 833).

${ }^{5}$ Es interesante notar cómo este modo de interactuar aparece luego en el Directorio para el Ministerio Pastoral de los Obispos "Apostolorum Successores" (2004), especialmente en los numerales 58-61.
} 


\section{La emergencia de una práctica y un estilo}

\subsection{Convergencia espiritual y profética}

El Celam fue el órgano facilitador de la práctica ambiental de hacer un camino identitario juntos. Hasta la fecha de la Conferencia el organismo había realizado once reuniones ordinarias, una cada año, y contaba con doce departamentos que prestaban asesoría y formación a la Iglesia del continente. Además, tenía cuatro institutos ubicados en distintas ciudades de la región dedicados a la investigación y había adelantado seis encuentros especializados que fueron preparando la orientación doctrinal hacia Medellín: Baños, Ecuador (5-8 de junio de 1966); Mar del Plata, Argentina (11-16 de octubre de 1966); Buga, Colombia (12-25 octubre de 1967); Melgar, Colombia (20-27 de abril de 1968), e Itapoã, Salvador de Bahía, Brasil (12-19 de mayo de 1968) (PARADA, 1975, p. 2938).

Este camino previo a Medellín fue gestando un estilo eclesial propio o eclesialidad vivida, con mecánicas de trabajo en conjunto y formas de proceder colegiadas. Se puede decir que "a través de esas instancias las personas se encuentran, se comunican experiencias, se analizan inquietudes, se genera vida, se empieza a ver en grande. Si se tiene en cuenta el aislamiento en el que se vivía y la falta de lugares de encuentro" (CALDERÓN, 1983, p. 19). Era una práctica novedosa porque nunca antes había tenido lugar una interacción sociocultural y eclesial de esta magnitud, y no encontraba en el Vaticano II su tematización, pues toda forma de intercambio en la Iglesia se regía, primariamente, por una lógica jurídica y una metafísica ontológica. Se preparaba así el paso de una institución eclesiástica que había estado caracterizada por ser monocultural, jurídica y romana, a otra de corte multicultural, carismática y regional, lo cual implicaba, necesariamente, buscar modos de integrar las diferencias locales en una unidad mayor en fidelidad al espíritu conciliar. 
El Concilio había desarrollado la categoría de colegialidad (LG 22-23), pero no la de sinodalidad, la cual fue muchas veces identificada con la actividad colegiada de los obispos en reuniones conciliares, lo que hacía que perdiera su sentido más amplio y los diversos niveles de su ejercicio en el Pueblo de Dios: entre obispos (affectus collegialis), entre obispos y presbíteros (communio sacramentalis en el sacerdocio ministerial), y en relación con los laicos (corresponsabilidad). Una de las grandes dificultades, que aún persiste, es cierta tendencia que no acepta la ampliación de la sinodalidad a una práctica consultiva de todos y no de unos pocos, y se reduce así a dos formas institucionales tradicionales: los concilios y los sínodos ${ }^{6}$. A partir de este modelo no se puede explicar lo que aconteció en Medellín. La palabra sinodalidad denota un affectus, una experiencia, un espíritu, una forma de interactuar entre las personas. El sínodo es un evento extraordinario que concretiza a esta forma de interactuar, pero no la colma. De ser así, tendría que seguirse tratando como un concepto derivado de la colegialidad simplemente o relacionado con la conciliaridad, que es lo que predominaba en la época de la Conferencia. De hecho, el mismo documento de Medellín describe "la celebración de Sínodos y la constitución, ya comenzada en muchos lugares, de los Consejos presbiterial y pastoral propiciados por el Concilio" (Pastoral de conjunto 3). Pero estas prácticas, por sí solas, no expresan lo que es la sinodalidad en sentido amplio y más propio.

La sinodalidad es el modo de ser y operar de la Iglesia que afecta a estilos de vida, instrumentos de discernimiento y estructuras de gobierno (ROUTHIER, 1994). Es una dimensión constitutiva de lo eclesial y no un acto puntual o método funcional. Presupone el principio de comunión que dota de identidad a la Iglesia, porque no se refiere solo a los distintos ministerios "en su función sacramental y jurisdiccional, sino a toda la realidad místico-sacramental de la Iglesia, que a nivel

\footnotetext{
6 “Non si dovrebbe estendere la nozione della sinodalità all'ambito del principio consultivo. Si correrebbe altrimenti il rischio di fare ultimamente riferimento senza parametri ecclesiologici ai modelli secolari e si trovarsi nuovamente dinanzi ad una costituzionalizzazione parlamentare dell'ufficio vescovile, oppure addirittura ad un mero parlamentarismo ecclesiale. Se sinodalità, intesa in senso stretto, indica solo i sinodi o concili classici, in senso più ampio dovrebbe allora ricomprendere soltanto le istituzioni, che non sono chiamate così e che però posseggono oggettivamente gli elementi costitutivi essenziali di un sinodo." (AYMANS, 1993, p. 40).
} 
ontológico es una communio cum Deo et hominibus, y a nivel estructural una communio ecclesiarum" (CORECCO, 1979, p. 1484). Al respecto, el Papa Pablo VI fue muy claro al explicar que, en la nueva mentalidad eclesial postconciliar, la noción de comunión no podía ser reducida a vínculos jurídicos o relaciones gradadas y jerárquicas, porque con ese vocablo se alude a la "Iglesia como una solidaridad profunda y orgánica (...) que nos hace consortes en la vida divina y nos hermana a todos en Cristo" (PABLO VI, 1969)7.

En Medellín, la experiencia de comunión eclesial -solidaria, filial y fraterna- estuvo acompañada del criterio de convergencia espiritual, es decir, de un modo de interactuar donde lo jurídico no es lo que garantiza el vínculo respecto a los juicios y decisiones formulados, como tampoco la votación de la mayoría, sino "un fenónemo de convergencia de los obispos entre ellos" (CORECCO, 1979, p. 1487) ${ }^{8}$, una "convergencia de circunstancias proféticas” como Landazuri Ricketts lo esgrimió, que daba direccionalidad y sentido a las decisiones capaces de expresar el bien común de los pueblos y canalizar una práctica pastoral en atención a la realidad histórica de los pobres. En el contexto de la Conferencia, la convergencia presupuso actitudes personales, ambientales y socioculturales, como la escucha y la consulta, y no solo el análisis frío de las circunstancias históricas.

El Concilio no alcanzó una clara articulación jurídica ni una noción de convergencia espiritual que enlazara la profecía del Pueblo de Dios y su sentido de la fe, con el discernimiento del colegio de obispos y la acción del Romano Pontífice. Una opción de la hermenéutica posconciliar fue utilizar la noción de

\footnotetext{
7 "Nella formazione della nuova mentalità ecclesiale, chiamiamola pure post-conciliare, dobbiamo sviluppare il senso della comunione, in cui, come membri della Chiesa, siamo inseriti (...). Vi è talvolta, ai nostri giorni, chi attende dal progresso della coscienza che la Chiesa oggi acquista di se stessa come ad una auspicata dissolvenza dei suoi rapporti e vincoli giuridici, che la costituiscono quale mistico corpo, visibile e organico, di Cristo nella realtà storica del mondo; ovvero vi è chi considera tale processo dottrinale come un trapasso dei poteri, onde la Chiesa si regge e adempie la sua missione, a profitto dei gradi inferiori rispetto a quelli superiori nel Popolo di Dio; noi guarderemo piuttosto alla Chiesa come a una solidarietà profonda ed organica; come a quella società, a quella comunione, 'coinonia' dite il termine ormai noto dell'Apostolo Giovanni, che ci fa consorti della vita stessa di Dio (cfr. 2 Petr. 1, 4), e che ci affratella tutti in Cristo (cfr. 1 lo. 1, 6-7)". (PABLO VI, 1969).

8 "La sinodalidad es la modalidad jurisdiccional por medio de la cual viene garantizada, a nivel de la interpretación autoritativa de la palabra, la unidad de los obispos al interno de la communio ecclesiarum" y cuya "fuerza jurídicamente vinculante de los juicios y las decisiones colegiales no es fruto de la fuerza formal del principio de mayoría, sino por un fenónemo de convergencia de los obispos entre ellos". (CORECCO, 1979, p. 1487).
}

Horizonte, Belo Horizonte, v. 16, n. 50, p. 482-516, maio/ago. 2018 - ISSN 2175-5841 
corresponsabilidad para referirse a las relaciones de participación que deben existir entre los miembros de la Iglesia. Este concepto, sin embargo, responde a relaciones verticales que se establecen entre laicos y obispos, derivadas de la communio hierarchica. Aun cuando puede dar cuenta de una práctica que ayude a estructurar la vida eclesial desde la communio, deja sin solucionar el modo específico y el grado de incorporación del laicado en la gestión del poder en la Iglesia y en el ejercicio ministerial. En sentido positivo, el término significa una evolución de una visión meramente colaborativa del laico con el obispo, a otra de participación en la responsabilidad de la Iglesia. Eugenio Corecco, uno de los primeros estudiosos del tema, habla de la corresponsabilidad como consecuencia práctica de la sinodalidad:

\begin{abstract}
si es verdad que la sinodalidad es la realidad ontológica y la modalidad técnico-institucional - diferente de cualquier forma secular de gestión comunitaria del poder- que cualifica el ejercicio de la corresponsabilidad ministerial de los obispos, es también verdad que esta encuentra su raíz, más allá del sacramento episcopal, también en la communio que conforma toda la experiencia eclesial: la de los pastores y la de los laicos. En cuanto práctica técnico-institucional de la communio, la sinodalidad puede implicar análogamente (suo modo et pro sua parte) también al ejercicio de la corresponsabilidad laical. (CORECCO, 1979, p. 1491).
\end{abstract}

Un dato que puede contribuir con una solución se encuentra en la Lumen Gentium cuando indica que la Iglesia universal se realiza -in quibus et ex quibusen las Iglesias locales (LG 23). Desde esta perspectiva se abre un camino para ver el fenómeno de la sinodalidad como una dimensión y un estilo que toca a todas las instancias y personas que hacen vida en las Iglesias locales, lugar que acoge la concreción de la Iglesia más amplia, incluidos los obispos, los presbíteros y los laicos9. Aquí rige, más bien, el principio de proporcionalidad, de tal modo que "los laicos participan suo modo et pro sua parte en el sacerdocio, el magisterio y la realeza de Cristo (LG 31,1)" (CORECCO, 1979, p. 1491). La proporcionalidad no se fundamenta en relaciones verticales o jerárquicas, sino en relaciones horizontales que operan sobre la base de la igual dignidad habilitada en todos por el bautismo y

\footnotetext{
9 "La estructura sinodal de las Iglesias locales, fundada sobre la participación de los presbíteros en la plenitud del orden episcopal, y sobre la communio hierarchica con el obispo, cabeza del presbiterio es, en consecuencia, solo análoga a la del colegio episcopal, en el que todos los obispos poseen de manera propia el ministerio eclesial sacramental y jurisdiccional, y no como participación o derivación del oficio primacial del Papa". (CORECCO, 1979, p. 1490).
}

Horizonte, Belo Horizonte, v. 16, n. 50, p. 482-516, maio/ago. 2018 - ISSN 2175-5841 
la diversidad de carismas y por funciones que de ella emanan para materializar la misión. Por ello, Medellín llama a que los integrantes de estas comunidades "viviendo conforme a la vocación a que han sido llamados, ejerciten las funciones que Dios les ha confiado, sacerdotal, profética y real”, y hagan de ellas "un signo de la presencia de Dios en el mundo (AG 15)" (Pastoral de conjunto 11). En este escenario se parte, pues, de la communio fidelium, cuya lógica es relacional, en fidelidad al espíritu conciliar de la eclesiología Pueblo de Dios que acentúa las dinámicas relacionales de responsabilidad y misión, antes que las jurídicas y ontológicas ${ }^{10}$.

Al poner en práctica el espíritu del Concilio, Medellín logra articular el sensus fidelium de todos y el munus docendi de la jerarquía para hacer posible que todos los asistentes participen en el consentimiento y ejerzan así la dimensión profética de la Iglesia. Se va logrando la singularis antistitum et fidelium conspiratio (Dei Verbum 10) o una singular sinergia entre todos los miembros de la asamblea a través del clima de diálogo y discernimiento que priva en la redacción de las conclusiones en conjunto. Esta conspiratio es decisiva para comprender cómo se fue articulando la sinodalidad en la Conferencia, más allá de determinar si hubo un ejercicio de la corresponsabilidad, una delegación de la función consultiva o saber quiénes tuvieron derecho o no al voto. En otras palabras, el espíritu sinodal que allí se manifestó supuso el modelo de Iglesia Pueblo de Dios que dio primacía al sensus fidei y al sensus fidelium (Lumen Gentium 12), y la infalibilidad in credendo de todo el Pueblo de Dios - vivida en una realidad histórica concretafue el marco sobre el cual se ejerció la infalibilidad in docendo de los pastores.

\footnotetext{
10 “En virtud de esta catolicidad, cada una de las partes colabora con sus dones propios con las restantes partes y con toda la Iglesia, de tal modo que el todo y cada una de las partes aumentan a causa de todos los que mutuamente se comunican y tienden a la plenitud en la unidad. De donde resulta que el Pueblo de Dios no solo reúne a personas de pueblos diversos, sino que en sí mismo está integrado por diversos órdenes. Hay, en efecto, entre sus miembros una diversidad, sea en cuanto a los oficios, pues algunos desempeñan el ministerio sagrado en bien de sus hermanos, sea en razón de la condición y estado de vida, pues muchos en el estado religioso estimulan con su ejemplo a los hermanos al tender a la santidad por un camino más estrecho" (Lumen Gentium 13).
}

Horizonte, Belo Horizonte, v. 16, n. 50, p. 482-516, maio/ago. 2018 - ISSN 2175-5841 


\subsection{De la corresponsabilidad a la sinodalidad}

La experiencia hasta ahora descrita condujo, necesariamente, a una articulación - de hecho más que de derecho, o más práctico-ambiental que teóricajurídica, y por tanto no carente de ambigüedades a la hora de su formulación- de todos los participantes a la luz de la escucha de la Palabra de Dios y de la escucha de ellos entre sí, para discernir el paso del Espíritu de Dios en nuestra historia. Por eso, más allá de entender lo que allí ocurrió como un acto distributivo de la corresponsabilidad eclesial, que tiende a establecer cooperaciones y define funciones con base en las diferencias ontológicas, se concede que se estaba practicando un estilo eclesial sinodal que permitió "en un trabajo común (...) la participación de todos según la diversidad y originalidad de los dones y servicios" (ROUTHIER, 1995, p. 69) ${ }^{11}$. El acento no se puso en ayudar y colaborar con los pastores, sino en trabajar en conjunto, por el bien común, eclesial y social.

Alberto Múnera, SJ, destaca cómo esta práctica de participación de todos por igual se manifestó en hechos tan simples como dejar que cada uno escogiera la comisión en la que quería trabajar según su capacidad. También en escuchar y deliberar en conjunto durante las sesiones plenarias:

El lunes 26 de agosto se dio comienzo a las labores con una hermosa misa concelebrada. En la primera sesión realizada por la noche, se instaló oficialmente la Conferencia con discurso de los tres copresidentes: el cardenal Antonio Samoré, el cardenal Landazuri, arzobispo de Lima, y monseñor Avelar Brandão, presidente del Celam. Los días 27, 28 y 29 se dedicaron a la exposición de las ponencias y a la reunión por seminarios para profundizar en los temas. El fin de estos seminarios no era obtener conclusiones para proponer a los plenarios, sino crear un clima de reflexión sobre la problemática latinoamericana. A partir del viernes 30 se comenzó a trabajar en comisiones pastorales. Para los seminarios se dividió a los participantes por orden alfabético, para las comisiones, se permitió que cada participante escogiera la que fuera de su gusto. El domingo primero de septiembre se dio comienzo en las horas de la tarde al primer plenario. Durante sus sesiones que se realizaron también

\footnotetext{
11 "La sinodalidad no propone solamente un modelo de intercambio y concertación sino, sobre todo, ella permite participar a todos, según su rango, en un trabajo común. Por lo tanto, este concepto garantiza una participación ordenada y orgánica, teniendo en cuenta la diversidad de funciones, lo que la corresponsabilidad no garantiza. La sinodalidad tiene el mérito de ejercer correctamente la participación de todos según la diversidad y la originalidad de los dones y los servicios. De modo aún más específico, la sinodalidad expresa el estado de cada uno; estado resultante de los sacramentos: bautismo-confirmación y orden." (ROUTHIER, 1995, p. 69).
}

Horizonte, Belo Horizonte, v. 16, n. 50, p. 482-516, maio/ago. 2018 - ISSN 2175-5841 
durante el lunes 2 y el martes 3, las diversas comisiones pastorales propusieron sus conclusiones. Terminada la exposición de estas, se procedió a las intervenciones de los participantes sobre los diversos puntos discutidos. (MÚNERA, 1968, p. 395).

Medellín logra insertar - de hecho- la práctica de la corresponsabilidad tripartita (colegio, presbiterado y laicado) en un novedoso proceso, único hasta ese momento en las prácticas eclesiales, que anticipó un estilo sinodal de la praxis colegial, razón por la cual la Conferencia ha sido considerada paradigmáticamente como "el único ejemplo de una recepción continental del Vaticano II" (SCHICKENDANTZ, 2012) ${ }^{12}$. Y podemos agregar: no determinado por el ámbito jurídico y jerárquico, al inaugurar un modo de ser Iglesia y una visión programática definida por un espíritu y un estilo sinodal que caracterizó al ejercicio de la colegialidad de modo ambiental, no tematizado. Este espíritu (BOTERO RESTREPO, 1982, p. 166) se tradujo en una "experiencia de comunión de todos y cada uno que es la Iglesia” y llevó a admitir la "unidad en las diferencias". Caben aquí las palabras de Beozzo: "Ningún otro continente tuvo un evento comparable al de Medellín, como un caso ejemplar de una recepción continental y colegiada del Vaticano II, realizada de manera fiel, pero al mismo tiempo selectiva y creativa en relación a las mayores inspiraciones del Concilio" (BEOZZO, 2005, p. 537).

El primero en reconocer, explícitamente, que algo nuevo había brotado fue el cardenal Landazuri Ricketts. En su discurso de clausura manifiesta que:

la palabra colegialidad, si le damos toda su honda exigencia teológica y pastoral, puede contribuir a precisar nuestra contestación. Durante estos días ha surgido con valentía, aunque sin contornos bien precisos, un hecho: América Latina comienza a tener una dinámica propia. En este hecho se sitúa nuestra colegialidad (...). Nosotros hemos recibido el Espíritu que el Señor prometió; en Él, nuestra colegialidad es un hecho y un acontecimiento. Por ello, la vivencia de estos días nos dice que esta Segunda Conferencia General, su espíritu, su nuevo estilo, se inicia cuando concluye. Es un punto de partida que nos ha hecho cobrar más honda conciencia de lo que somos. La colegialidad no exige la proximidad física. Por ello, nuestra respuesta de estos días es firme esperanza de que continuaremos viviendo la unidad en la pluralidad. (LANDAZURI RICKETTS, 1969, p. 249).

\footnotetext{
${ }^{12}$ El autor refiere el origen de esta expresión en Escalante (2002, p. 79).
} 
Landazuri Ricketts describe el ejercicio de la colegialidad en términos de vivencia y acontecimiento que permiten lograr "la unidad en la pluralidad". Habla de un espíritu que determina y define el modo de proceder colegialmente. Por ello, la colegialidad, a su juicio, discurre desde su dinámica interna y relacional, y no gradada o hierarchica. En razón de esto, puede adelantar que "no exige la proximidad física" sino que se consuma en relaciones y actitudes:

Nuestra respuesta de estos días es firme esperanza de que continuaremos viviendo la unidad en la pluralidad. Oración, reflexión, diálogo, preocupación. Han sido actitudes características durante estas jornadas. Han de perdurar en nuestro corazón ahora que retornamos a nuestras Iglesias locales. (LANDAZURI RICKETTS, 1969, p. 248).

Diez años más tarde, Bernard Franck identificará ese espíritu como sinodalidad -tal vez haya sido el primero en hacerlo. Franck aporta dos dimensiones del fenómeno que se cumplen en la asamblea. La primera es la comunión entre las Iglesias locales, y la segunda el reconocimiento de la dinámica relacional que resulta de un acto o evento eclesial. En sus palabras, la sinodalidad “designa los enlaces y las relaciones de una Iglesia particular a otra, más allá de las fronteras nacionales o de las circunscripciones eclesiásticas existentes" (FRANCK, 1978, p. 76). De este modo, podemos decir que el Celam realiza, de forma única, la dimensión sinodal de la Iglesia en Medellín al ser capaz de crear este modo de interactuar entre las Iglesias locales. Aún más, siguiendo a Franck puntualizamos que:

La esencia de la sinodalidad, sin embargo, es un espíritu en lugar de un principio. Es una de las manifestaciones privilegiadas del espíritu cristiano que reposa esencialmente en la fraternidad humana que, a su vez, se deriva del reconocimiento de la paternidad de Dios, creador de todos los hombres a quienes concede su ser (hijos en el Hijo por el Espíritu Santo). Esta fraternidad, consecuencia y fruto de una doble gracia divina, se expresa mediante la comunión de los corazones y la humanidad de los espíritus. (FRANCK, 1978, p. 77).

De ahí que Landazuri Ricketts pueda alegar que lo que aconteció en Medellín "no exige proximidad física" y "ha de perdurar en nuestro corazón”. Se acentúan, entonces, la relación, los procesos, un espíritu y una forma de proceder e 
interactuar basados en la participación, en la colaboración y en la corresponsabilidad en todos los niveles con el fin de alcanzar "la unidad en la pluralidad" del conjunto, y no de uno o de pocos, a través de

La escucha recíproca, el intercambio y la comunicación, el compartir y la solidaridad, el deseo de llegar a un consenso, a una convicción común. Esto requiere la voluntad de colaborar y cooperar, de aceptar y de acoger, de dar y de recibir. Esto supone relaciones impregnadas de respeto y de caridad, de humildad y de pobreza. Así es el espíritu sinodal. (FRANCK, 1978, p. 77).

Al final, se trata de desarrollar un ambiente y una actitud de escucha, de acogida fraterna, capaz de desencadenar un proceso colectivo - de hecho o de derecho- de discernimiento y convergencia entre las personas. El testimonio de Mejía va en este sentido:

Aquí vivimos, trabajamos y rezamos por quince días, hasta el 7 de setiembre. Las trescientas personas que componen o atienden la Conferencia fraternizan en la mesa, en la celebración litúrgica y en las discusiones. Semejante nivelación de cardenales, arzobispos, religiosas, civiles, hombres y mujeres, es ya un progreso y un anticipo. Ninguna conferencia de Iglesia hubiera podido ser así hace cinco años. Y confieso que nadie parece incómodo. La liturgia contribuye, como es su papel y su eficacia propia. La mayoría concelebra (no todos, por desgracia), lo cual significa que de repente más de doscientos celebrantes salen en procesión de la sacristía triple para ocupar lugares en el óvalo elegante de la iglesia, con el altar al fondo. Un laico lee la epístola. Se canta bien y mucho. Se comulga bajo las dos especies. Se usan los nuevos cánones. Se da la paz a todos. Se ora de veras, y nos transformamos. El Instituto de Liturgia del Celam, responsable de esta obra de arte del culto, demuestra lo que vale y hace una catequesis con los hechos. (MEJÍA, 1968, p. 653).

La descripción que ofrece Gilles Routhier centra el sentido exacto de esta sinodalidad:

La sinodalidad, que es una dimensión constitutiva de la Iglesia y pertenece a su propia naturaleza, apela, por tanto, a las prácticas, las figuras institucionales y los procedimientos que permitan su realización. De lo contrario, ella se reduce a un sentimiento vago (...). Encontramos, por una parte, prácticas de escucha, consulta y diálogo y, por otra parte, una figura institucional capaz de realizar la sinodalidad. Tres acciones o prácticas describen concretamente lo que es el diálogo: expresar la opinión, escuchar y tomar consejos. (ROUTHIER, 2016, p. 695-696).

Horizonte, Belo Horizonte, v. 16, n. 50, p. 482-516, maio/ago. 2018 - ISSN 2175-5841 
Medellín reconoce que este estilo sinodal que completa a la colegialidad es constitutivo del ser eclesial, por lo que pide "renovar y crear nuevas estructuras en la Iglesia que institucionalicen el diálogo y canalicen la colaboración entre los obispos, sacerdotes, religiosos y laicos" (Mensaje de los pueblos de América Latina). A tal fin, interpreta que debe haber un cambio en la mentalidad reinante que haga del diálogo una dinámica permanente cuyo carácter comunitario sea esencial a la pastoral en conjunto. La Conferencia resalta lo relacional y ambiental, los procedimientos por medio de los cuales se producen los verdaderos vínculos que dan sentido a la experiencia cristiana, para poder "alcanzar a todas las esferas del Pueblo de Dios, creando en obispos, sacerdotes, religiosos y laicos, movimientos y asociaciones, una sola conciencia eclesial" (Pastoral de conjunto 35). Lo resume así:

la renovación personal implica un proceso de continua mentalización y 'aggiornamento', desde un doble punto de vista: a) teológico-pastoral, fundamentado en los documentos conciliares y en la teología vigente; $\mathrm{y} b$ ) pedagógico, proveniente de un continuo diálogo apoyado en la dinámica de grupo y en una revisión sobre la acción mediante tipos de pastoral, tendiente a crear un auténtico sentido comunitario, sin el cual es totalmente imposible una genuina pastoral de conjunto. (Pastoral de conjunto 35).

De hecho, las críticas de la asamblea a las estructuras vigentes en la Iglesia que considera que no son fieles a la orientación del Concilio están expresadas en un lenguaje que refleja la necesidad de dar vida a un espíritu o forma sinodal de proceder:

Entre los hechos de signo negativo figuran los siguientes: a) inadecuación de la estructura tradicional en muchas parroquias para proporcionar una vivencia comunitaria; b) sensación bastante generalizada de que las curias diocesanas son organismos burocráticos y administrativos; c) desazón en muchos sacerdotes, proveniente de no encontrar un lugar decisivo en algunas crisis sacerdotales, como también, por analogía de situaciones, en las crisis de un número considerable de religiosos y laicos; d) actitudes particularistas de personas o instituciones en situaciones que exigen coordinación; e) casos de aplicación desacertada de la Pastoral de conjunto o de la planificación, sea por improvisación o incompetencia técnica, sea por excesiva valoración de los 'planes', sea por una concepción demasiado rígida y autoritaria de su puesta en práctica. (Pastoral de conjunto 4). 


\section{Método y ambiente de trabajo}

\subsection{De la escucha a la asunción colectiva}

La novedad de la colegialidad ampliada que según Mejía fue "fecundada y completada”, para Beozzo, como dijimos antes, "estuvo esbozada en torno a la mecánica de trabajo adoptada en Medellín y, en parte, en las votaciones realizadas” (BEOZZO, 1998, p. 833). Pero más allá de "adaptar el tono y el método de la Gaudium et Spes”, el ambiente de discernimiento que se fue gestando, movido por una disposición de escucha y de diálogo en pequeños grupos y sesiones plenarias, permitió, incluso, que de las mismas discusiones in situ surgiera la idea de trabajar sobre dieciséis áreas que culminaría en la redacción de los dieciséis documentos que forman parte del texto conclusivo (MCGRATH, 1989, p. 165). McGrath recuerda que "se decidió no llegar a la Conferencia con un texto ya elaborado al que solo se le harían enmiendas. El método que se siguió fue muy diferente. Unos pocos primeros días se dedicarían a escuchar, y luego discutir, en pequeños grupos y en sesiones plenarias" (MCGRATH, 1989, p. 164)13.

Esta flexibilidad en un grupo eclesial que apenas empezaba a asimilar los cambios del Concilio es asombrosa, porque, en el fondo, se estaba apostando a la capacidad de todos en la asamblea de crear algo nuevo a la luz del ambiente de trabajo puesto en marcha. El hecho de no partir de un método previo que luego se aplicaría hizo posible que, aun cuando los participantes estaban divididos entre miembros efectivos - con derecho a voto- y simples participantes - sin derecho a

\footnotetext{
${ }^{13}$ El texto completo cita que: "de antemano, se decidió no llegar a Medellín con un texto ya elaborado al que solo se le harían enmiendas. El método que se siguió fue muy diferente. Unos pocos primeros días se dedicarían a escuchar, y luego discutir, en pequeños grupos y en sesiones plenarias, siete ponencias. Las dos primeras ponencias versaban sobre los 'signos de los tiempos' y sobre su interpretación cristiana en América Latina. Para ello se adaptaría el tono y el método de la 'Gaudium et Spes', como ejemplo que debía seguirse en toda la sesión. Esto fue favorablemente aceptado." (MCGRATH, 1989, p. 164).
}

Horizonte, Belo Horizonte, v. 16, n. 50, p. 482-516, maio/ago. 2018 - ISSN 2175-5841 
voto (MÚNERA, 1968, p. 397-398) ${ }^{14}$ - se requiriera siempre de la aprobación del total de asistentes y no solo de los obispos, pues las tareas de reflexión y redacción se realizaban en las comisiones y en equipos pequeños, y luego pasaban a ser discutidas por todos en las plenarias (JARAMILLO MARTÍNEZ, 1998, p. 14-15) ${ }^{15}$, en las que estuvieron presentes "junto con los obispos, muchos sacerdotes, religiosos y laicos, abriendo un nuevo estilo de asunción colectiva de la tarea de la Iglesia” (TOVAR, 1983, p. 16). Esta dinámica ponía en práctica una auténtica conspiratio que fue posible porque ocurrió lo que Routhier denomina como una disposición para escuchar y aprender, que es la base de toda forma de proceder sinodal y, en última instancia, no puede ser prescrita ya que depende del modo en que nos relacionamos y nos tratamos los unos a los otros:

La vida sinodal requiere, por tanto, otro elemento, una disposición para escuchar, es decir, tomar en serio y acoger con simpatía lo que se dice. Esta es una actitud. La sinodalidad no puede reducirse a una mecánica formal, como si el establecimiento de figuras institucionales y la implementación de procedimientos y prácticas consiguientes fueran suficientes para que pudiéramos vivir. Por el contrario, también puede existir donde los procesos formales no están establecidos. En este nivel infrainstitucional, depende en gran medida de la capacidad de escuchar y la voluntad de aprender de los demás. Se basa en aquellos que realizan la función de presidir, en el entendimiento de su ministerio y en la conciencia de esta función de presidir la Iglesia de Dios, que ha sido confiada a sus ministros ordenados, sin separarlos (ni empoderarlos) de los otros miembros de la Ecclesia Dei. Por lo tanto, la sinodalidad, que pide actitudes y es producto de un espíritu, depende en gran medida de las habilidades relacionales de quienes ejercen cargos y de su capacidad de situarse como hermanos, amigos, colaboradores y cooperadores. (ROUTHIER, 2016, p. 701).

\footnotetext{
${ }^{14}$ Sobre los votos hay que indicar que participaban por derecho 247 personas, aunque algunas no pudieron acudir. El tipo de participante fue distribuido en diversas categorías. Múnera distingue en sus Crónicas entre miembros efectivos, que eran aproximadamente 130, comprobables por el número de sufragios que hubo en las votaciones. Luego estaban los simples participantes, que tenían voz pero no voto. Sumaban cerca de 110, cifra que se puede ratificar por la diferencia entre el número de sufragios y el total de los participantes por derecho. En este grupo se inscribían los secretarios ejecutivos y los presidentes de los institutos del Celam, los miembros no sacerdotes de la junta directiva de la CLAR, los invitados como expertos, los invitados especiales y los observadores no católicos. Los laicos, incluidos invitados como el padre Pedro Arrupe SJ, monseñor Gabriel Montalvo (Cosiglio per gli Affari Publici della Chiesa), monseñor Luis Bernardo Pozo (director del Instituto de Pastoral del Celam) y las religiosas no votaron. Sin embargo, como venimos diciendo, sobre este diseño no se puede entender la ampliación o no de la colegialidad, como tampoco lo que será el ejercicio sinodal en Medellín. El tema de las votaciones se puede revisar en Múnera (1968, p. 397-398).

15 “La metodología que la asamblea aprobó para su ritmo de trabajo abarcó la doble modalidad de reuniones por grupo y de sesiones plenarias. Para las primeras, los obispos se distribuyeron según dieciséis temas que abarcaban las más fuertes preocupaciones. En torno a cada uno de ellos constituyeron las comisiones de trabajo. Era tarea y misión de cada comisión la elaboración de un documento sobre el aspecto determinado. En las sesiones plenarias se sometía a la aprobación del conjunto total de asistentes lo convenido en las reuniones de grupos. Fue entonces esta asamblea plenaria la que en última instancia vio la unidad de los temas particulares e impartió a ellos su aprobación hasta configurar el documento llamado: La Iglesia en la actual transformación de América Latina a la luz del Concilio. Medellín: conclusiones." (JARAMILLO MARTíNEZ, 1998, p. 14-15).
}

Horizonte, Belo Horizonte, v. 16, n. 50, p. 482-516, maio/ago. 2018 - ISSN 2175-5841 
Según Landazuri Ricketts, esta actitud ha de conceder primacía a la escucha del Espíritu de Dios, que es quien guía, renueva, genera armonía e impulsa una dinámica propia, tal como Jesús hizo en la sinagoga de Nazaret (Lc 4,16-20):

El Espíritu de Dios, que con admirable providencia, guía al curso de los tiempos y renueva la faz de la Tierra, no es ajeno a esta evolución. Y este Espíritu, que fortalece constantemente nuestra estructura orgánica y nuestra concordia, nos impulsa a realizar la dinámica propia de la Iglesia latinoamericana. (LANDAZURI RICKETTS, 1969, p. 248).

La disposición para escuchar y aprender en conjunto marcó el estilo de Medellín. Creemos que el acto fundacional de este ejercicio sinodal fue la “capacidad para escuchar fielmente la Palabra de Dios" (Formación del clero 9) por medio de las palabras y los hechos humanos (Dei Verbum 2) en los que Dios se autocomunica. Se escucha la Palabra de Dios de forma situada, es decir, en un contexto sociocultural específico que pasa a ser lugar teológico de su recepción y actualización, para ser transmitida de un modo nuevo. El cardenal Landazuri Ricketts lo explica con propiedad no exenta de belleza:

\begin{abstract}
Escuchar primeramente la voz de Dios, de su Iglesia, de nuestra conciencia para reconocer y cumplir mejor nuestra misión pastoral como obispos. Saber escuchar, también, la voz del mundo. Pues estamos tal vez acostumbrados a una visión 'clerical' del mundo. A veces se produce en nosotros casi espontáneamente, recelo, desconfianza, temor, ante lo que es llamado, no sé si muy exactamente, 'lo profano' y, sin embargo, la Palabra de Dios se hizo hombre y habita entre nosotros dando sentido a todo cuanto de humano existe y se realiza. Por ello, siempre que escuchamos al hombre escuchamos a Cristo; siempre que nos preocupamos del hombre, nos preocupamos de Cristo. Y en la medida en que nos encontramos con los hombres, aprendiendo y sabiendo ir hacia ellos, nos encontramos con el mismo Señor. (LANDAZURI RICKETTS, 1968).
\end{abstract}

Es sobre este acto de escucha que Medellín asume el principio de reformabilidad permanente de la Iglesia (Unitatis Redintegratio 6) y afirma que "toda revisión de las estructuras eclesiales en lo que tienen de reformable, debe hacerse para satisfacer las exigencias de situaciones históricas concretas, pero también con los ojos puestos en la naturaleza de la Iglesia. La revisión que debe llevarse a cabo hoy en nuestra situación continental, ha de estar inspirada y 
orientada por dos ideas directrices muy subrayadas en el Concilio: la de comunión y la de catolicidad (Lumen Gentium 13)" (Pastoral de conjunto 5). La necesidad de reexaminar las estructuras eclesiales y sociales no partió de una autorreflexión de la Iglesia, sino de la reflexión sobre su misión en el mundo latinoamericano y caribeño. Por tanto, se aleja de toda autorreferencialidad y visión clericalista, y reconoce que "para un análisis de este tipo, sería necesario escuchar más a los técnicos y a los laicos" (Pastoral de las élites 4). Es un estilo que va haciendo propia una escucha horizontal, que reconoce no solo lo más inherente a cada uno, sino también lo profano, lo distinto y en apariencia no religioso. Por ello, es una escucha abierta, no basada en relaciones jerárquicas u ontológicas, como era tradicional en la Iglesia. De este modo, los laicos estarán presentes en las distintas comisiones que se integraron no como auxiliares de los obispos y sacerdotes, sino aportando, con autonomía y autoridad, las reflexiones y los contenidos pertinentes en cada comisión según su experticia.

En este espíritu de escucha horizontal, lo primero que hizo la asamblea fue abrir los oídos a una serie de datos acerca de la realidad latinoamericana que no eran tan conocidos en los ambientes eclesiales tradicionales y que lograron dar cabida a la expresión de una fuerte sensibilidad social y a una clara orientación pastoral que marcarán las reflexiones en todos sus documentos (CAMPS, 1969, p. 21-22) ${ }^{16}$. El obispo Samuel Ruiz recordó que lo que estaba en juego en esta recepción conciliar era "cambiar nuestra concepción y actitud de una Iglesia que se coloca fuera del mundo, frente y contra el mundo. La Iglesia es el Pueblo de Dios comprometido en la historia; la Iglesia está en el mundo" (RUIZ, 1968, p. 167). De ahí que la disposición primera que los obispos proponen es la escucha para servir: “deseamos respetar sinceramente a todos los hombres y escucharlos para servirlos

\footnotetext{
16 "A diferencia del Concilio, y superando su método, la asamblea de Medellín no quiso deliberar desde un principio sobre esquemas ya hechos. Para tomar como punto de partida un conocimiento lo más exacto posible de los problemas del continente, la Conferencia inició sus trabajos oyendo una impresionante 'Visión sociográfica de América Latina', del sociólogo brasileño Alfonso Gregory, secretario para América Latina de la Federación de Centros de Estudios sociorreligiosos. Del conjunto abrumador de datos y cifras sobre la situación demográfica, económica, social y religiosa de América Latina, el mismo P. Gregory dedujo las conclusiones que habían de marcar profundamente los trabajos de la asamblea: la marginalidad de la mayoría de la población con respecto a las minorías privilegiadas, y sobre todo la marginalidad del continente en el contexto mundial, es cada vez mayor, lo cual configura una situación de violencia instalada, que no puede dejar de provocar una contra violencia por reacción." (CAMPS, 1969, p. 21-22).
}

Horizonte, Belo Horizonte, v. 16, n. 50, p. 482-516, maio/ago. 2018 - ISSN 2175-5841 
en sus problemas y angustias" (Pobreza de la Iglesia 18).

Este contacto inicial en conexión con los datos de la realidad del continente, puso en marcha una serie de formas de proceder en la dinámica de trabajo y provocó un deseo auténtico por conocer más acerca de lo escuchado para tratar de comprenderlo y discernirlo a la luz de la Palabra. Routhier identifica a este tipo de métodos y ambientes de trabajo como propiamente sinodales:

estos procedimientos son de varios tipos: deben favorecer la difusión más completa de la información, permitir la consulta y la expresión serena de los diversos puntos de vista, apoyar el estudio que lleva a la maduración de las ideas, enmarcar el intercambio y deliberación que conducen a la toma de decisiones, fomentar la retroalimentación para comprender las orientaciones tomadas, etc. Los procedimientos invitan a reuniones, intercambios y diálogos, estableciendo relaciones e interacciones típicas entre personas. (ROUTHIER, 2016, p. 700-701).

La acción de escucha discurre en reconocimiento y fidelidad al sensus fidei del Pueblo de Dios, pues es el mismo Dios quien se autocomunica en él. La respuesta colegiada es la de interpretar lo escuchado con una atención especial al grito de los pobres. Haciendo suyas las palabras de Pablo VI a los campesinos en Colombia, los obispos reunidos en Medellín dicen: "Oímos el grito que sube de vuestro sufrimiento" (Pobreza de la Iglesia 2). Este acto colegiado de discernimiento situado se explica en el Documento Básico Preliminar (DBP) del siguiente modo:

Nuestra fe nos lleva a ver en el hombre, en cada hombre, y en la comunidad que se desarrolla en la historia, un movimiento hacia una creciente personalización, es decir, una verdadera conciencia de la dignidad del hombre en la apertura hacia el mundo, hacia los otros y hacia Dios. (cf. GS 6). Tal movimiento brota de una iniciativa divina y realiza en los acontecimientos de este mundo el plan de salvación de Dios. Esta salvación tiene su origen en la comunidad del Padre, del Hijo y del Espíritu Santo (LG 2-4), y se realiza por la mediación de la Iglesia donde los hombres encuentran su salvación "no individualmente y aislados entre sí, sino en el seno de la comunidad santa, mediante la constitución de un Pueblo, que conoce al Señor en la verdad y le sirve santamente (LG 9). El centro de este designio es Jesucristo, quien por su muerte y su Resurrección transforma el universo y hace posible este acceso de los hombres a su verdadera plenitud humana; una plenitud que abarca al hombre en su totalidad, cuerpo y espíritu, individuo y sociedad, persona y cosmos, tiempo y eternidad. (CELAM, 1993, p. 18).

Horizonte, Belo Horizonte, v. 16, n. 50, p. 482-516, maio/ago. 2018 - ISSN 2175-5841 
En el ejercicio sinodal de la colegialidad destacan dos dimensiones de la escucha: el discernimiento y la interpretación propios del colegio episcopal reunido en conjunto, y la conspiratio de todos los miembros del Pueblo de Dios - como hemos indicado anteriormente. Se trata, en otras palabras, de mantener la dinámica conciliar entre el uno (el Papa), los muchos (los obispos) y todos (el pueblo), un esfuerzo posible cuando se quieren conciliar posiciones divergentes a partir de una conspiratio capaz de lograr consensos eclesiales que se conviertan en convicciones vinculantes para la vida de la Iglesia. Es una visión que incorpora la recepción de Dei Verbum 10 en el acto de admitir que el depósito de la Palabra de Dios ha sido confiado a "todo el Pueblo de Dios, unido a sus pastores", quienes han de "constituir un consenso singular" (fidelium conspiratio), y establecer así una relación esencial y recíproca entre sensus fidei y magisterio. Solo desde esta configuración kerygmática situada que parte de la escucha de la Palabra en la historia de los pueblos se puede, entonces, lograr traducir el mensaje a las formas actuales en que se recibe. Una auténtica aplicación del principio conciliar de pastoralidad de la doctrina que

Impone un trabajo permanente para que se haga perceptible cómo el Mensaje de Salvación, contenido en la Escritura, la liturgia, el Magisterio y el testimonio, es hoy palabra de vida. No basta, pues, repetir o explicar el Mensaje. Sino que hay que expresar incesantemente, de nuevas maneras, el 'Evangelio' en relación con las formas de existencia del hombre, teniendo en cuenta los ambientes humanos, éticos, y culturales y guardando siempre la fidelidad a la Palabra revelada. (Catequesis 15).

En este contexto, es importante destacar la importancia de la liturgia diaria ${ }^{17}$ al interior de un ambiente y una forma sinodal de proceder desde la escucha, el discernimiento y la integración comunitaria. La liturgia se organizó de tal manera que permitía inaugurar con oración los temas que serían discutidos en la asamblea. No se puede entender la sinodalidad en Medellín sin la articulación del ámbito comunitario y su visión de conjunto del día a partir de la liturgia. Especialmente hay dos novedades: la lectura de la Palabra cada día en sintonía con los temas a

\footnotetext{
${ }^{17}$ Para el desarrollo de la liturgia en la Conferencia se puede leer a Scatena (2007, p. 175-216).
} 
discutir en los grupos y las plenarias, y la participación en la Eucaristía de los observadores no católicos. En palabras de Boaventura Kloppenburg, lo que impregnaba la sesión de

\begin{abstract}
Un tono de piedad comunitaria y de solemnidad sencilla y devota. Un hecho notable, quizás único en la historia, sucedió en la concelebración del 5 de septiembre por la tarde, cuando los observadores (un obispo anglicano, un pastor luterano, un pastor metodista y un hermano de Taizé) recibieron la santa comunión bajo las dos especies. Era un momento conmovedor y rico; tal vez el inicio de una nueva fase de un movimiento de unidad efectiva entre los cristianos. (KLOPPENBURG, 1968, p. 626).
\end{abstract}

Se comprende que no sea tan frecuente el uso de citas bíblicas en los documentos escritos si el día a día se vivía a partir de la lectura y la reflexión de la Palabra en conjunto a través de la liturgia. Si hablamos de un ambiente sinodal, no tenemos que quedarnos con el texto escrito y publicado como cerrado y absoluto, sin entender que fue fruto del clima humano y eclesial en el que se gestó, y que permitió una comunicación real entre los miembros a todos los niveles. En fin, el texto es siempre entendido en el marco de un acontecimiento mayor.

\title{
4.2 Una comunicación real, ascendente y descendente
}

Al profundizar en la eclesiología del Pueblo de Dios, Medellín pone en marcha un proceso de recepción que parte de la communio fidelium en convergencia espiritual con la communio hierarchica y realizado en convergencia profética dentro de la communio ecclesiarum. La reciprocidad permanente de las tres instancias y la manera en que se articularon (convergencia espiritual y profética) logró producir una comunicación real o una forma permanente de sinodalidad ambiental que se manifestó no solo en la propia vivencia en la asamblea, como hemos venido describiendo, sino también en las exigencias para la reforma o revisión (Pastoral de conjunto 5) de las estructuras eclesiales. Esto llevó -incluso sin que ello significara una clara conciencia de sus implicaciones- a una inversión eclesiológica en cuya base estarían pequeñas comunidades locales en las que se concretaría la Iglesia universal. En lo social se propuso una acción 
correlativa que conduciría a la construcción del tejido sociocultural y político partiendo de la base hasta llegar a las élites. Para la Conferencia, una auténtica reforma eclesial no se reducía al cambio de las estructuras en sí o de las personas que las dirigieran, sino que buscaría concentrarse en el modo de articular el flujo comunicacional o forma sinodal de trabajar entre ellas y entre sus integrantes. Por ello,

Es esencial que todas las comunidades eclesiales se mantengan abiertas a la dimensión de comunión católica, en tal forma que ninguna se cierra sobre sí misma. Asegurar el cumplimiento de esta exigencia es tarea que incumbe particularmente a los ministros jerárquicos, y en forma especialísima a los obispos, quienes, colegialmente unidos con el Romano Pontífice, su cabeza, son el principio de la catolicidad de las Iglesias. Para que dicha abertura sea efectiva y no puramente jurídica, tiene que haber comunicación real, ascendente y descendente, entre la base y la cumbre (Pastoral de conjunto 8).

Una tal eclesialidad o articulación de la colegialidad de forma sinodal se construye desde adentro y desde abajo (comunidades de base y parroquias) hacia arriba (estructuración jerárquico-carismática). Las palabras inaugurales de Landazuri Ricketts fueron inspiradoras: "A lo largo de estos días de trabajo estemos muy atentos a la actitud cristiana - porque es de Cristo- de tomar el mundo tal como es, desde abajo. Solo así seguiremos los caminos de la encarnación que ha iniciado Jesús" (LANDAZURI RICKETTS, 1968). Su consejo llevó a ordenar la reflexión siempre a partir de una "unidad en la misión y diversidad en los carismas, servicios y funciones" (Iglesia visible 7-8; Sacerdotes 7) para permitir la participación diferenciada del Pueblo de Dios. Se trataba de una distinción no jerárquica, sino horizontal y recíproca de los miembros en razón de la "triple función profética, sacerdotal y real de Cristo" en todo bautizado (Iglesia visible 8). Sobre esta base era posible una forma de proceder "orgánica y articulada" (Pastoral de conjunto 9) por la que cada integrante aportara algo a los otros de modo complementario y específico de su función y lugar social y eclesial. Así, por ejemplo, se habló de lo más propio del "compromiso del laico en el mundo por la liberación y la humanización” (Iglesia visible 9.13), lo que se expresa de manera aún más nítida en el siguiente texto: 
Los ministerios que llevan anexa la función pastoral, episcopado y presbiterado deben ejercer siempre en espíritu colegial, y así obispos y presbíteros, al tener que actuar siempre como miembros de un cuerpo (colegio episcopal o presbiterio, respectivamente), 'ejemplar' de comunión: forma facti gregis. (Pastoral de conjunto 7).

La "corresponsabilidad entre obispos y presbíteros" (Sacerdotes 15) se entiende que es un ejercicio que ha de tener lugar bajo la forma facti gregis, lo que compromete al cuerpo colegial para que se mantenga al servicio del pueblo, en medio de la grey como testigo, en permanente colaboración, y no por encima, como señores privilegiados. La alusión aquí a 1 Pedro 5,2-3 da el tono: "Apacentad la grey de Dios que está entre vosotros, cuidando de ella, no por fuerza, sino voluntariamente; no por ganancia deshonesta, sino con ánimo pronto; no como teniendo señorío sobre los que están a vuestro cuidado, sino siendo ejemplos de la grey". La sinodalidad es lo que da vida a las estructuras pues permite "participar fraternalmente de la común dignidad de hijos de Dios" (Pastoral de conjunto 6), por lo que "los diversos ministerios, no solo deben estar al servicio de la unidad de comunión, sino que a su vez deben constituirse y actuar en forma solidaria” (Pastoral de conjunto 7).

Se puede afirmar que el espíritu conciliar de Lumen Gentium 37 se profundiza en Medellín a través del fomento de actitudes que ayudan a pensar, discernir y planificar todo en conjunto. El Concilio había establecido el sentido de esta comunicación real y orgánica de la base hacia arriba al expresar que los laicos

tienen la facultad, más aún, a veces el deber, de exponer su parecer acerca de los asuntos concernientes al bien de la Iglesia (...). Los sagrados Pastores reconozcan y promuevan la dignidad y responsabilidad de los laicos en la Iglesia. Recurran gustosamente a su prudente consejo, encomiéndenles con confianza cargos en servicio de la Iglesia y denles libertad y oportunidad para actuar; más aún, anímenles incluso a emprender obras por propia iniciativa.

La Conferencia asume que este modelo comienza con las pequeñas comunidades cristianas de base que son "el primero y fundamental núcleo eclesial, que debe, en su propio nivel, responsabilizarse de la riqueza y expansión de la fe, 
como también del culto que es su expresión”. Ellas constituyen, sobre todo, la "célula inicial de estructuración eclesial y foco de la evangelización, y actualmente factor primordial de promoción humana y desarrollo" (Pastoral de conjunto 10). La razón de estos centros de base es que permiten ejercer el espíritu fraterno de la sinodalidad, algo que no se encuentra hoy en día en una estructura de parroquias territoriales sin comunidades ambientales:

La vivencia de la comunión a que ha sido llamado, debe encontrarla el cristiano en su comunidad de base; es decir, una comunidad local o ambiental, que corresponda a la realidad de un grupo homogéneo, y que tenga una dimensión tal que permita el trato personal fraterno entre sus miembros. (Pastoral de conjunto 10).

El nuevo tejido eclesial asume a la parroquia, también en el marco del espíritu sinodal, como un "conjunto pastoral vivificador y unificador de las comunidades de base" (Pastoral de conjunto 13); la integra como un ente que facilita la interacción, pues no tiene un fin en sí misma, como espacio cerrado, sino en tanto comunidad de comunidades - del modo análogo en que la Iglesia universal es una institución en medio de otras en la sociedad y contribuye con el desarrollo local. En este esquema se entiende más diáfanamente la afirmación anterior: "La vivencia de la comunión a que ha sido llamado, debe encontrarla el cristiano en su comunidad de base (...); que tenga una dimensión tal que permita el trato personal fraterno entre sus miembros" (Pastoral de conjunto 10). Y la razón profunda responde a que "la comunidad se formará en la medida en que sus miembros tengan un sentido de pertenencia de "nosotros"' (Pastoral popular 13). Es este nosotros lo que permitirá una real comunicación ascendente y descendente en alineación con las dinámicas de pertenencia y reciprocidad que crea.

La Conferencia también prevé otras formas que pueden institucionalizar el espirítu sinodal para replicar el sentido de escucha en conjunto y asunción colectiva. Pero todas las formas posibles deben ser planteadas con la perspectiva de generar procesos de convergencia espiritual y profética entre la totalidad de los miembros del Pueblo de Dios. Así, se nos habla de la necesidad de crear consejos 
presbiteriales y pastorales. "Si el Consejo Presbiterial debe ser el principal canal del diálogo del obispo con sus presbíteros, el Consejo Pastoral debe serlo de su diálogo con toda su diócesis" (Pastoral de conjunto 18), y en ambos consejos ha de funcionar, a suo modo et pro sua parte, la colaboración y la representatividad del "Pueblo de Dios en la diversidad de sus condiciones y estados de vida" (Pastoral de conjunto 18) (BEOZZO, 1998, p. 833) ${ }^{18}$. Es un camino que conduce a una auténtica desclericalización y descentralización de la Iglesia para rescatar su dimensión propiamente misionera y favorecer la coparticipación en su gobierno (Pastoral de conjunto 19).

\section{Conclusión}

El acontecimiento de Medellín supuso una recepción del Concilio que llevó a la Iglesia latinoamericana a posicionarse como una Iglesia fuente, una Iglesia que no solo había creado una forma colegial de interactuar a nivel continental con la creación del Celam, sino que inauguró un espíritu de ser y trabajar y un modo de interacción que dieron paso a una forma sinodal de proceder que caracteriza su identidad. En fin, esta nueva forma eclesial emergente sólo se entiende cuando comprendemos el modo cómo los participantes en la Conferencia vivieron e interpretaron ese momento histórico a la luz de la historia de la salvación. Por ello, Monseñor Eduardo Pironio fue muy claro al decir que ellos vivieron Medellín como un acontecimiento salvífico. Podemos decir que, en último término, este espíritu y sentido es lo que verdaderamente posibilitó la gestación de un auténtico clima sinodal:

Este acontecimiento salvífico -en cuya preparación y realización participó tan activamente el CELAM - marcó una etapa nueva y decisiva. Fue verdaderamente un hecho histórico, en el que el Espíritu del Señor escribió para nosotros -y para la Iglesia entera- un capítulo fundamental de la historia de la salvación. (PIRONIO, 1973, p. 192).

\footnotetext{
${ }^{18}$ Como afirma Beozzo (1998, p. 833): "o que ali aconteceu aponta na direção de que todos os membros do povo de Deus tenham voz e voto nos assuntos pastorais, seja nos conselhos pastorais paroquiais, nos conselhos diocesanos de pastoral, seja na prática já consagrada das assembleias diocesanas para aprovação das diretrizes e prioridades pastorais de uma Igreja particular".
}

Horizonte, Belo Horizonte, v. 16, n. 50, p. 482-516, maio/ago. 2018 - ISSN 2175-5841 
Sin embargo, son aún muchas las personas y las comunidades que desconocen este acontecimiento que dividió a nuestra historia eclesial en un antes y un después. Por ello, es preciso insistir en hacer memoria de la interrelación que ocurrió entre todos los asistentes a la Conferencia y las comunidades cristianas de la Arquidiócesis de Medellín, porque tal vez sea ese un ejercicio hoy desdibujado, y nos recuerda que las comunidades no deben ser visitadas por los obispos solo para presidir una eventual liturgia, sino que ellos están llamados a ir para facilitar una auténtica disposición de todos los miembros del Pueblo de Dios a escucharse y aprender mutuamente a partir de un diálogo sincero sobre la realidad local y a partir de la Palabra. Así lo manifiesta Julio Jaramillo Martínez:

Los obispos celebraron dos actos con la comunidad cristiana de Medellín. El primero de ellos fue una celebración de la Palabra. Tuvo lugar la noche del viernes 30 de agosto en el estadio Atanasio Girardot de la ciudad. Una cantidad de personas pertenecientes a las parroquias de la Arquidiócesis se hizo presente en el acto. El segundo ocurrió el domingo inmediatamente siguiente. Los prelados asistentes se desplazaron a las parroquias para acompañar a las comunidades en la celebración del día del Señor. Se produjeron entonces diferentes tipos de reuniones con los líderes de las parroquias. El diálogo en ellas versó no solo sobre el quehacer de la Conferencia sino además sobre la realidad religiosa de la Iglesia local. (JARAMILLO MARTÍNEZ, 1998, p. 15).

Medellín sigue invitándonos, proféticamente, a fecundar y completar el ejercicio de la colegialidad en el marco de un espíritu y una forma de proceder sinodal que ha de definir nuestro modo de ser Iglesia.

\section{REFERENCIAS}

AYMANS, W. Sinodalità: forma di governo ordinaria o straordinaria nella Chiesa. In: AYMANS, W.; BERTOLINO, R.; MANGELS, G. (Ed.). Diritto canonico e comunione ecclesiale. Saggi di diritto canonico in prospettiva teologica. Torino: Giappichelli Editore, 1993. p. 33-49.

BEOZZO, J. O. A Igreja do Brasil no Concílio Vaticano II: 1959-1965. São Paulo: Paulinas, 2005.

BEOZZO, J. O. Medellín: inspiração e raízes. Revista Eclesiástica Brasileira, Petrópolis, n. 232, p. 822-850, 1998.

Horizonte, Belo Horizonte, v. 16, n. 50, p. 482-516, maio/ago. 2018 - ISSN 2175-5841 
BOTERO RESTREPO, J. Celam: elementos para su historia. Bogotá: Editorial Copiyepes, 1982.

BRANDÃO VILELA, A.; PIRONIO E. F. Palabras de Presentación. In: CONSEJO EPISCOPAL LATINOAMERICANO (CELAM). La Iglesia en la actual transformación de América Latina a la luz del Concilio. Ponencias. Bogotá: Secretariado General del CELAM, 1968.

CALDERÓN, A. J. En ruta hacia Medellín. Páginas, Lima, n. 58, p. 18-25, 1983.

CAMPS, J. Prólogo. In: CELAM. Iglesia y liberación humana. Los documentos de Medellín. Barcelona: Editorial Nova Terra, 1969.

CELAM. Documento Básico Preliminar para la II Conferencia General del Episcopado Latinoamericano. Revista Medellín (Separata especial), Bogotá, n. 76, p. 1-52, 1993.

CELAM. II Conferencia General del Episcopado Latinoamericano. Documento de Trabajo. Bogotá: Consejo Episcopal Latinoamericano, Agosto 26 - Septiembre 7, 1968.

CELAM. La Iglesia en la actual transformación de América Latina a la luz del Concilio. Ponencias. Bogotá: Consejo Episcopal Latinoamericano, 1968.

CORECCO, E. Sinodalità. In: BARBAGLIO, G.; DIANICH, S. (Ed.). Nuovo Dizionario di Teologia. Roma: Edizione Paoline, 1979. p. 1466-1495.

DE LORA, C. Del Concilio a Medellín, hoy. Horizonte, Belo Horizonte, v. 9, n. 24, p. 1233-1245, 2011.

DIRECTORIO para el Ministerio Pastoral de los Obispos “Apostolorum Successores”, 2004. Disponible en:

<http://www.vatican.va/roman_curia/congregations/cbishops/documents/rc_con_cbish ops_doc_20040222_apostolorum-successores_sp.html>. Acceso en: 10 maio 2018.

ESCALANTE, L. La estructura jurídica y sinodal del Consejo Episcopal Latinoamericano (CELAM) y de la Reunión de los Obispos de América. Roma: Pontificia Universidad de la Santa Cruz, 2002.

FERRÉ, Methol. La Iglesia en América Latina: del Vaticano II a Medellín (19621968). Disponible en:

<http://www.metholferre.com/obras/articulos/capitulos/detalle.php?id=87>. Acceso en: 21 jan. 2018.

FRANCK, B. Les expériences synodales après Vatican II. Communio: revue catholique internationale 3, Lisboa, v. 3, p. 64-78, maio 1978.

GERA, L. Reflexiones teológicas sobre la Iglesia. In AZCUY, V.; GALLI, C.; GONZÁLZEZ, M. Escritos teológico-pastorales de Lucio Gera. I: del preconcilio a la Conferencia de Puebla (1956-1981). Buenos Aires: Ágape, 2006. 
GUTIÉRREZ, G. Actualidad de Medellín. Páginas, Lima, n. 152, p. 6-17, 1998.

JARAMILLO MARTÍNEZ, J. Una crónica de Medellín. Cuestiones Teológicas y Filosóficas, n. 63, p. 7-20, 1998.

KLOPPENBURG, B. A Segunda Conferência Geral do Episcopado Latino-Americano. Revista Eclesiástica Brasileira, Petrópolis, n. 28, p. 623-626, 1968.

KUSCH, R. Geocultura del hombre americano. Buenos Aires: Colección Estudios Latinoamericanos, 1976.

LANDAZURI RICKETTS, J. Discurso de clausura de la II Conferencia General del Episcopado Latinoamericano. In: CONFERENCIA GENERAL DEL EPISCOPADO LATINOAMERICANO. Signos de renovación: recopilación de documentos postconciliares de la Iglesia en América Latina. Lima: Comisión Episcopal de Acción Social, 1969.

LANDAZURI RICKETTS, J. Discurso inaugural en Bogotá (26 de agosto de 1968). In: CELAM. La Iglesia en la actual transformación de América Latina a la luz del Concilio. Ponencias. Bogotá: Consejo Episcopal Latinoamericano, 1968.

LIMA VAZ, H. C. DE. Igreja-reflexo vs. Igreja-fonte. Cadernos Brasileiros, São Paulo, n. 46, p. 17-22, 1968.

LUCIANI, R. El Papa Francisco y la teología del pueblo. Madrid: PPC, 2016.

LUCIANI, R. Los signos de los tiempos como criterio hermenéutico fundamental del quehacer teológico. Atualidade Teológica, Rio de Janeiro, n. 52, p. 37-57, 2016.

MCGRATH, M. Algunas reflexiones sobre el impacto y la influencia permanente de Medellín y Puebla en la Iglesia de América Latina. Medellín, n. 58-59, p. 152-179, 1989.

MCGRATH, M. Cómo viví el Concilio y el Postconcilio. Bogotá: Paulinas, 2000.

MEJÍA, J. El pequeño Concilio de Medellín (2). Criterio, n. 41, p. 686-689, 1968.

MÚNERA, A. Crónica de la II Conferencia General del Episcopado Latinoamericano. Theologica Xaveriana (Revista Javeriana), n. 349, p. 393-404, 1968.

PABLO VI. Discorso all'udienza generale, 12 novembre 1969. Disponible en: <https://w2.vatican.va/content/paul-vi/it/audiences/1969/documents/hf_pvi_aud_19691112.html>. Acceso en: 18 maio 2018.

PABLO VI. Discorso nel X anniversario del Celam, 23 novembre 1965.

PARADA, H. Crónica de Medellín. Bogotá: Indo-American Press Service, 1975. 
PIRONIO, E. Naturaleza, misión y espiritualidad del CELAM. In: PIRONIO, E. Escritos Pastorales. Madrid: BAC, 1973.

ROUTHIER, G. Évangile et modèle de sociabilité. Laval Théologique et Philosophique, v. 51, n. 1, p. 59-75, 1995.

ROUTHIER, G. La synodalitè dans l'Église locale. Scripta Theologica, n. 48, p. 987-706, 2016.

ROUTHIER, G. Le défi de la communion: une relecture de Vatican II. Montreal: Médiaspaul, 1994.

RUGGIERI, G. Chiesa sinodale. Roma: Editori Laterza, 2017.

RUIZ, G. S. La evangelización en América Latina. In: CELAM. La Iglesia en la actual transformación de América Latina a la luz del Concilio. Ponencias. Bogotá: Consejo Episcopal Latinoamericano, 1968.

SCATENA, S. Sapere ascoltare e sapere essere?: la liturgia alla conferenza di Medellín. Cristianesimo nella storia, v. 28, n. 1, p. 175-216, 2007.

SCHICKENDANTZ, C. Único ejemplo de una recepción continental del Vaticano II. Teología, n. 108, p. 25-53, 2012.

TOVAR, C. Quince años de Medellín. Reflexión, n. 55, p. 16-19, 1983.

VITALI, D. Verso la sinodalità. Magnano: Edizioni Qiqajon Comunità di Bose, 2014. 